\title{
PROCESSING OF GENETIC DATA UNDER GDPR: UNRESOLVED CONFLICT OF INTERESTS
}

\author{
by \\ PETRO SUKHOROLSKYI ${ }^{*}$ VALERIIA HUTSALIUK ${ }^{* *}$
}

Over the last decades, developments in the fields of genetics and bioinformatics caused a marked increase in the processing of human genetic data by various companies and institutions. This results in the adoption of several international documents and the emergence of legal norms on the protection of genetic data. The paper examines how and to what extent the interests and rights of the data subject with regard to the processing of genetic data are protected in the European Union. It is concluded that under the GDPR this task is implemented through classifying genetic data as sensitive, reliance on anonymisation and pseudonymisation, as well as introduction of the procedure of data protection impact assessment. Nevertheless, given the unique characteristics of genetic data distinguishing them from other categories of personal data, these measures cannot be regarded as sufficient and effective. The paper argues that current EU data protection legislation creates favourable conditions for genetic research, thereby ensuring particular public interests, but does not establish a special regime for genetic data processing appropriate to potential threats in this field and risks to the rights of data subjects.

\section{KEY WORDS}

Anonymisation, Balancing of Interests, Data Protection Impact Assessment, General Data Protection Regulation, Genetic Data, Pseudonymisation, Research Exemption, Sensitive Data, Special Categories of Personal Data

\footnotetext{
petro.m.sukhorolskyi@lpnu.ua, Associate Professor at Lviv Polytechnic National University, Department of International Information, Ukraine.

* valeriiahutsaliuk@gmail.com, Lviv Polytechnic National University, Ukraine.
} 


\section{INTRODUCTION}

The emergence at the national and international levels of legal rules protecting the rights of natural persons regarding the processing of their personal data is both a direct consequence of the rapid development of information technology in the second half of the twentieth century and an attempt to respond appropriately to the threats posed by it. However, science does not stand still and the information revolution we are witnessing is probably far from over. In this regard, the legislative and other public authorities are forced to constantly respond to the changing environment in which personal data protection rules adopted by them must be applied. This is not an easy task, as they have to act in the face of uncertainty of many factors and to balance between the various vital public and private interests, none of which can be ignored. ${ }^{1}$

The European Union is recognized as the world's leader in creating advanced standards of personal data protection. The new General Data Protection Regulation 2016/679 2 (hereinafter referred to as the "GDPR") adopted by it in 2016, which came into force in 2018, replacing the former Directive $95 / 46 / E C^{3}$, is precisely such an attempt to respond to the challenges of the time and to create a solid foundation for the protection of various private and public interests in this field. One of the innovations of the GDPR is the provisions concerning human genetic data the processing of which has radically increased in recent years. ${ }^{4}$ This fact has not been overlooked by other international organizations concerned with issues such as development of science and personal data protection.

1 Borry, P. et al. (2018) The Challenges of the Expanded Availability of Genomic Information: An Agenda-Setting Paper. The Journal of Community Genetics, 9 (2), pp. 103-116.

2 Regulation (EU) 2016/679 of the European Parliament and of the Council of 27 April 2016 on the protection of natural persons with regard to the processing of personal data and on the free movement of such data, and repealing Directive 95/46/EC (General Data Protection Regulation). Official Journal of the European Union (2016/L-119/1) 4 May. Available from: https://eur-lex.europa.eu/legal-content/EN/TXT/PDF/?uri=CELEX:32016R0679\&from= EN [Accessed 7 March 2020].

3 Directive 95/46/EC of the European Parliament and of the Council of 24 October 1995 on the protection of individuals with regard to the processing of personal data and on the free movement of such data. Official Journal of the European Communities (1995/L-281/31) 23 November. Available from: https://eur-lex.europa.eu/legal-content/EN/TXT/PDF /?uri=CELEX:31995L0046\&from=en [Accessed 7 March 2020].

4 For instance, according to Regalado, by 2019 more than 26 million consumers had added their DNA to four leading commercial databases. If this trend continues, this figure is expected to rise to 100 million within 24 months. Regalado, A. (2019) More than 26 million people have taken an at-home ancestry test. MIT Technology Review. [online] Available from: https://www.technologyreview.com/s/612880/more-than-26-million-people-have-taken-anat-home-ancestry-test/ [Accessed 7 March 2020]. 
In particular, in 2003, the General Conference of UNESCO adopted a landmark document entitled the International Declaration on Human Genetic Data. Even earlier, in 1997, the Committee of Ministers of the Council of Europe adopted the Recommendation $R$ (97) 5 on the Protection of Medical Data, containing much reference to genetic data. In 2018, the provision on genetic data was added to the Convention for the Protection of Individuals with regard to Automatic Processing of Personal Data (ETS. No. 108) through the adoption of the Protocol (CETS No. 223) amending the Convention.

Although the protection of genetic information derived from human tissue is not yet the subject of special interest of a wide range of legal scholars, it is still an important issue for detailed examination because it opens up entirely new problems and makes one think about the perspectives of the whole contemporary system of personal data protection. In such a case of conflict between two important interests, it is difficult to reconcile them in order to achieve a stable and harmonious balance. On the one hand, there are interests of individuals whose genetic data are processed, as well as significant public interests related to the control over extremely powerful technologies and the specific ways they are applied. On the other hand, there are equally important interests related to conducting research in the fields of genetics and bioinformatics that are crucial for overcoming certain urgent problems of humanity. Accordingly, there exist legitimate expectations of society for an increase of scientific knowledge, which are highlighted in the GDPR. ${ }^{5}$

Taking all these things into consideration, our main task is to investigate how and to what extent these interests are protected in the current EU legislation. In particular, we tried to find out whether the level of protection of natural persons with regard to the processing of their genetic data increases over time and whether it responds to the current realities and challenges posed by the rapid development of science and technology.

Over the last three decades, interrelated issues such as the legal protection of human genetic data, the maintenance of genetic privacy, and the prevention of genetic discrimination have repeatedly attracted attention of researchers from various scientific disciplines. Among the scholars who made a significant contribution to research in this field are $P$. Billings, L. Bygrave, M. Gerstein, L. Gostin, Y. Erlich, B. Korf, T. Lemke, M. Taylor. Since

\footnotetext{
5 See Recital 113 of the GDPR.
} 
the GDPR was adopted, a number of academic works (in particular, by P. Borry, A. de Paor, K. Pormeister, M. Shabani, L. Quinn, P. Quinn) directly related to the processing of personal genetic data under the current EU legislation have been presented.

\section{GENETIC DATA AS A SPECIAL CATEGORY OF PERSONAL DATA}

The GDPR contains several provisions concerning genetic data and the risks associated with their processing. Besides, the very definition of personal data is supplemented by a reference to genetic factors as one of the identifiers of a natural person. ${ }^{6}$ In contrast, genetic data or characteristics are not mentioned in the Directive 95/46/EC at all. However, this does not mean that at the time when the Directive was in force, such data did not fall under the EU legislation or was not considered as personal data. In its documents the Working Party on the protection of individuals with regard to the processing of personal dataan advisory body established under Article 29 of the Directive (hereinafter referred to as the Article 29 Working Party) made repeated references to the issues related to genetic data and highlighted the need to ensure that they are properly handled. This matter is even addressed by a separate act of the Working Party entitled the Working Document on Genetic Data, which was adopted in $2004 .^{7}$ It is of special significance for us as it makes it possible to compare the EU's genetic data protection policy before and after the adoption of the GDPR.

The threats associated with the processing of genetic data are briefly mentioned in the GDPR. In particular, Recitals 71 and 75 outline the potential risks and possible discriminatory effects on natural persons on the basis of genetic or health status. However, it is doubtful whether these provisions provide a comprehensive and detailed picture of the threats in this field. For comparison, this issue is covered in greater detail in the Working Document of the Article 29 Working Party. It provides, inter alia, the following characteristics of genetic data distinguishing it from other categories of data and causing the necessity of greater protection:

\footnotetext{
See Article 4 (1) of the GDPR.

According to Article 30 of the Directive 95/46/EC, the Working Party is authorised to examine any question covering the application of the national measures adopted under the Directive and to advise on all matters relating to the protection of individuals with regard to the processing of personal data, as well as to perform other functions.
} 
(1) genetic data reveal information not only about the data subject, but also about his or her blood relatives and certain groups of persons to which he or she belongs;

(2) as a rule, genetic information is unknown to the bearer him/herself and does not depend on the bearer's individual will since genetic data are non-modifiable;

(3) genetic data can be easily obtained from raw materials;

(4) genetic data may reveal more information in the future and be used by an increasing number of agencies for various purposes. ${ }^{8}$

The document also mentions the risks of genetic data re-use that might occur, inter alia, through additional analysis of stored biological materials and provides detailed information on threats of using such data for the purposes connected with employment, ${ }^{9}$ insurance, identification, medical and scientific research. Besides, the Article 29 Working Party highlights

"the present absence of regulatory framework in the field of the on-line 'genetic testing direct to the public'". ${ }^{10}$

According to the GDPR, genetic data means

"personal data relating to the inherited or acquired genetic characteristics of a natural person which give unique information about the physiology or the health of that natural person and which result, in particular, from an analysis of a biological sample from the natural person in question". ${ }^{11}$

8 Article 29 Data Protection Working Party. (2004) Working Document on Genetic Data, 12178/03/EN WP 91, 17 March, pp. 4-5. Available from: https://ec.europa.eu/justice/article29/documentation/opinion-recommendation/files/2004/wp91_en.pdf [Accessed 9 March 2020].

9 As for employment, the draft Regulation, adopted by Parliament at the first reading, stipulated that data collection for the purpose of genetic testing and analyses shall be prohibited in this field as a matter of principle. However, the relevant article was later removed. European Parliament legislative resolution of 12 March 2014 on the proposal for a regulation of the European Parliament and of the Council on the protection of individuals with regard to the processing of personal data and on the free movement of such data (General Data Protection Regulation). Official Journal of the European Union (2017/C-378/399) 9 November, Article 82 (c). Available from: https://eur-lex.europa.eu/legal-content/EN/TXT/ PDF/?uri=CELEX:52014AP0212\&from=EN [Accessed 7 March 2020].

10 Article 29 Data Protection Working Party. (2004) Working Document on Genetic Data, 12178/03/EN WP 91, 17 March, pp. 13-14. Available from: https:/ec.europa.eu/justice/ article-29/documentation/opinion-recommendation/files/2004/wp91_en.pdf [Accessed 9 March 2020].

11 See Article 4 (13) of the GDPR. 
It should be noted that in the draft Regulation, submitted by the European Commission in 2012, genetic data are defined in a different way as

"all data, of whatever type, concerning the characteristics of an individual which are inherited or acquired during early prenatal development". ${ }^{12}$

The Working Document of the Article 29 Working Party sets out various definitions of genetic data which are taken from the Council of Europe Recommendation R (97) 5, Law of Luxembourg on the protection of persons with regard to the processing of personal data, and the International Declaration on Human Genetic Data adopted by UNESCO. ${ }^{13}$ However, only in the last document as well as in the GDPR interpretation of genetic data is linked to the analysis of biological materials which should be carried out to obtain such data. This approach has been criticized by some researchers. In particular, Shabani and Borry consider this issue problematic because of the activities of DNA testing, medical, and other companies that use genealogical data gathered through both genetic investigation and various questionnaires filled out by their clients. ${ }^{14}$ In addition, other factors like phenotypic characteristics may indicate some features of the personal genome. Taylor rightly points out that such information is far from being precise but this does not mean we can ignore its significance as well as potential harm caused by the improper use of such data. ${ }^{15}$

Such a narrow interpretation of genetic data is not fully justified, especially if taking primarily into account the interests of the data subject. ${ }^{16}$ It is not excluded that in the future this definition can cause additional difficulties in the protection of individual's rights as he/she will have

12 European Commission. (2012) Proposal for a Regulation of the European Parliament and of the Council on the protection of individuals with regard to the processing of personal data and on the free movement of such data (General Data Protection Regulation), COM/2012/011 final 2012/0011 (COD), 25 January, Article 4 (10). Available from: https://eur-lex.europa.eu/legalcontent/EN/TXT/PDF/?uri=CELEX:52012PC0011\&from=EN [Accessed 9 March 2020].

13 Article 29 Data Protection Working Party. (2004) Working Document on Genetic Data, 12178/03/EN WP 91, 17 March, p. 4. Available from: https://ec.europa.eu/justice/article-29/ documentation/opinion-recommendation/files/2004/wp91_en.pdf [Accessed 9 March 2020].

14 Shabani, M. and Borry, P. (2018) Rules for processing genetic data for research purposes in view of the new EU General Data Protection Regulation. European Journal of Human Genetics, 26 (2), p. 152.

15 Taylor, M. (2012) Genetic Data and the Law: A Critical Perspective on Privacy Protection. Cambridge: Cambridge University Press, p. 46.

16 See also: De Paor, A. (2017) The European Union and Protection of Genetic Information. In: De Paor, A. (ed.). Genetics, Disability and the Law: Towards an EU Legal Framework. Cambridge: Cambridge University Press (Cambridge Disability Law and Policy Series), p. 230. 
to prove that personal genetic data result from an analysis of a biological sample. Otherwise, provided that it is not medical data, he may be deprived of the rights guaranteed to the individual with regard to his personal data classified as sensitive. What is even more surprising is that the definition of genetic data under the GDPR refers to the

"analysis of a biological sample from the natural person in question",

that is, samples of a particular person who is the data subject. If a biological sample is taken from the blood relative of a particular individual (even in a case if the probability that they both have the same gene is extremely high), the result from the analysis of this sample will not be considered as this individual's genetic data. Consequently, he or she will have no rights related to this genetic information. In contrast, the definition of human genetic data from the aforementioned UNESCO Declaration, which can be considered as the most authoritative universal document in this field, only mentions that such information has to be "obtained by analysis of nucleic acids or by other scientific analysis" without making any reference to a biological material of a particular person. ${ }^{17}$

Thus, the GDPR does not take into account the considerations previously mentioned in the Working Document, namely the fact that genetic data reveal information about an individual's blood relatives, and does not ensure the protection of the rights of such persons. ${ }^{18}$ The Article 29 Working Party was generally inclined to recognize some relatives' rights regarding the processing of genetic data (but without classifying them as data subjects) and noted the need for further study of this issue. ${ }^{19}$ To address this problem, Taylor proposes to classify these persons as "secondary data subjects" and to clearly enshrine their rights. ${ }^{20}$ It should also be recalled that the GDPR does not apply to deceased persons ${ }^{21}$ and this creates additional risks for the aforementioned "secondary data subjects", since in such a case

17 United Nations Educational, Scientific and Cultural Organization. (2003) International Declaration on Human Genetic Data, SHS/BIO/04/1, 16 October, Article 2 (i). Available from: http://portal.unesco.org/en/ev.php-URL_ID=17720\&URL_DO=DO_TOPIC\&URL_SECTION =201.html [Accessed 9 March 2020].

18 Article 29 Data Protection Working Party. (2004) Working Document on Genetic Data, 12178/03/EN WP 91, 17 March, p. 4. Available from: https://ec.europa.eu/justice/article-29/ documentation/opinion-recommendation/files/2004/wp91_en.pdf [Accessed 9 March 2020].

19 Op. cit., pp. 8-9.

20 Taylor, M. (2012) Genetic Data and the Law: A Critical Perspective on Privacy Protection. Cambridge: Cambridge University Press, pp. 104, 117.

21 See Recitals 27 and 158 of the GDPR. 
the data is not protected by personal data protection law at all (unless the member states have adopted the relevant rules in accordance with the provisions of Recital 27).

Another important aspect is the protection of the rights of natural persons regarding their biological samples, which are the source of the bulk of genetic information the acquisition of which becomes more easily and cheaply available. That is, the threat to the person stemmed from unlawful handling of his or her biological samples could potentially be more serious than the one resulting from illegal processing of fragmented information about personal genome. Nevertheless, in accordance with the established principles governing personal data protection, the GDPR deals only with the data processing and the handling of biological samples falls outside of its scope. In this regard, Taylor proves the fallacy of the artificial distinction between the categories of interpreted genetic data (resulting from the analysis of a biological sample) and interpretable one (including biological samples), especially when the ultimate goal of regulation is to effectively protect the privacy of the individuals. ${ }^{22}$ In any case, the justification of a separate regulation for the handling of genetic samples and the processing of data derived from these samples is questionable, given the fact that even companies collecting and using a large amount of genetic information often consider both as personal data. ${ }^{23}$

One of the key accomplishments of the GDPR is the clear and unambiguous assignment of genetic data to special categories of personal data. This imposes additional obligations on data controllers and is designed to guarantee the interests and rights of natural persons. Yet, in the past, the vast majority of genetic data was already classified as personal data belonging to special categories, namely to health data. In this regard, the Working Document on Genetic Data states that genetic data may reveal not only information on an individual's health status, but also his or her ethnic origin and, therefore, may also belong to the category of sensitive data. Besides, the Working Party drew the general conclusion that considering the

22 Taylor, M. (2012) Genetic Data and the Law: A Critical Perspective on Privacy Protection. Cambridge: Cambridge University Press, pp. 158-165.

23 For instance, MyHeritage, one of the world's largest genealogy research services companies, in its privacy policy statement, which contains the list of personal data that are collected and processed, places DNA samples, DNA Results, and DNA Reports in one group. MyHeritage. (2019) MyHeritage Privacy Policy. [online] Available from: https://www.my heritage.com/privacy-policy [Accessed 9 March 2020]. 
"extremely singular characteristics of genetic data and their link to information that may reveal the health condition or the ethnic origin, they should be treated as particularly sensitive data"

within the meaning of the provisions of Directive 95/46/EC relating to special categories of personal data. ${ }^{24}$ It is undeniable that classifying all personal genetic data as belonging to special categories and distinguishing them as a separate category is a step forward in ensuring adequate protection of the rights of individuals. On the other hand, unlike the Working Document, the GDPR does not recognize special characteristics and the exceptional sensitivity of genetic data, making it necessary to introduce special rules and measures. It only places genetic data in the extensive list of special categories of personal data, along with political opinions, religious or philosophical beliefs, trade union membership, etc. For comparison, in Convention No.108, as amended by the Additional Protocol of $2018,{ }^{25}$ genetic data are classified as one out of the four groups of special categories of personal data. Moreover it is listed first and, at least, is clearly separated from all other categories. ${ }^{26}$

\section{SAFEGUARDS FOR THE RIGHTS OF THE DATA SUBJECT}

Taking into account the provisions of the GDPR and other relevant official documents ${ }^{27}$ it can be concluded that the task of guaranteeing the rights of individuals regarding the processing of their genetic data is implemented under the EU legislation through:

(a) classifying such data as sensitive;

24 Article 29 Data Protection Working Party. (2004) Working Document on Genetic Data, 12178/03/EN WP 91, 17 March, p. 5. Available from: https://ec.europa.eu/justice/article-29/ documentation/opinion-recommendation/files/2004/wp91_en.pdf [Accessed 9 March 2020].

25 Council of Europe. (2018) Convention 108+ (Modernised Convention for the Protection of Individuals with Regard to the Processing of Personal Data), 21 June, Article 6 (1). Available from: https://www.europarl.europa.eu/meetdocs/2014_2019/plmrep/COMMITTEES/LIBE/ DV/2018/09-10/Convention_108_EN.pdf [Accessed 7 March 2020].

26 It is worth noting that the lack of any other special provisions on genetic data in Convention $108+$ at a time when the urgency and significance of the matter is highlighted in many studies and genetic data processing has become widespread is, obviously, its serious drawback.

27 For example, European Parliament. Committee on Petitions. (2019) Petition No 0733/2018 by J.B. (Portuguese) on improving the protection of genetic data related to European Union citizens, 15 March. Available from: https://www.europarl.europa.eu/doceo/document/PETI-CM637225_EN.pdf [Accessed 7 March 2020]. 
(b) introduction of the procedure of data protection impact assessment;

(c) reliance on anonymisation and pseudonymisation of genetic data.

\subsection{ADDITIONAL GUARANTEES REGARDING SENSITIVE DATA} Article 9 of the GDPR relating to the handling of special categories of personal data defines the legal grounds for their processing, in the absence of which such data cannot be processed. Although the list is extensive, given the specific nature of the use of genetic data, (1) the explicit consent of the data subject and

(2) "archiving purposes in the public interest, scientific or historical research purposes or statistical purposes in accordance with Article 89 (1)"28

can be considered as two main grounds for their processing which cover the vast majority of cases. Comparing these provisions with the corresponding Article 8 of Directive 95/46/EC, it is noticeable that the list of legal grounds for the processing of special categories of data has been significantly broadened and supplemented, inter alia, by the aforementioned subparagraph on scientific research purposes relating directly to genetic data.

Another important difference is that the Directive specifying a short list of legal grounds enables member states to expand it for reasons of substantial public interest. ${ }^{29}$ In contrast, the GDPR provides a broader range of grounds, but allows states to

"introduce further conditions, including limitations, with regard to the processing of genetic data, biometric data or data concerning health". ${ }^{30}$

In assessing both options from the perspective of the data subject, it can be concluded that the new European standard established by the GDPR is less favourable to an individual, especially given the conventionality of borders when it comes to scientific research or the Internet service industry. ${ }^{31}$ In realizing their right to introduce further conditions with regard to the processing of genetic data member states are limited by other

See Article 9 (2) (a) and (j).

See Article 8 (4) and Recital 34 of Directive 95/46/EC.

${ }^{30}$ See Article 9 (4) of the GDPR.

31 Pormeister, K. (2017) Genetic data and the research exemption: is the GDPR going too far? International Data Privacy Law, 7 (2), p. 146. 
provisions of the GDPR. In particular, Recital 9 refers to the negative effects of differences in national legislation on personal data protection, which prevent the free flow of data and constitute an obstacle to the pursuit of economic activities at the level of the Union. In addition, Recital 10 makes it clear that Article 9 (4) refers specifically to the possibility of introducing "national provisions to further specify the application of the rules" of the GDPR and not to a substantial deviation from its certain provisions (for instance, from those permitting the processing of genetic data for scientific research purposes without the consent of the data subject).

Other guarantees ensuring an adequate level of protection of the rights of individuals with regard to the processing of special categories of personal data, which are provided for in the GDPR, include the prohibition of automated individual decision-making based on such data (except in cases when the data subject has given his or her explicit consent or it is necessary for reasons of substantial public interest) ${ }^{32}$ and the obligation of the controller and the processor to designate a data protection officer in the case where their core activities consist of processing on a large scale of special categories of data. ${ }^{33}$ The draft Regulation submitted in 2012 comprised another important provision that empowered the European Commission
"to adopt delegated acts [...] for the purpose of further specifying the criteria, conditions and appropriate safeguards for the processing of the special categories of personal data". ${ }^{34}$

Obviously, such powers would make it possible to create uniform binding and detailed standards relating to the processing of genetic data within the EU, which would take into account the specific nature of this field. However, they, like most of the other powers of the Commission to adopt delegated acts pursuant to Article 92, were excluded in the later versions of the draft Regulation.

32 See Article 22 (4) of the GDPR.

33 See Article 37 (1) (c) of the GDPR.

34 European Commission. (2012) Proposal for a Regulation of the European Parliament and of the Council on the protection of individuals with regard to the processing of personal data and on the free movement of such data (General Data Protection Regulation), COM/2012/011 final 2012/0011 (COD), 25 January, Article 9 (3). Available from: https://eur-lex.europa.eu/legalcontent/EN/TXT/PDF/?uri=CELEX:52012PC0011\&from=EN [Accessed 9 March 2020]. 


\subsection{DATA PROTECTION IMPACT ASSESSMENT}

The wording of Recital 89 leads to the conclusion that it is necessary to apply different approaches to the protection of individuals when it comes to the different types of personal data. In this regard, special emphasis should be placed on creating

"effective procedures and mechanisms which focus [...] on those types of processing operations which are likely to result in a high risk to the rights and freedoms of natural persons". ${ }^{35}$

One of such procedures provided for in Recitals 90 and 91 is a data protection impact assessment, the responsibility for which in accordance with Recital 84 remains with the data controller. Article 35 of the GDPR explicitly states that an impact assessment is required in the case of the "processing on a large scale of special categories of data". ${ }^{36}$ The grounds and procedures of such assessment are described in detail in the Guidelines on Data Protection Impact Assessment adopted in 2017 by the Article 29 Working Party. ${ }^{37}$ This document explains, inter alia, what factors need to be taken into consideration when determining whether the processing is carried out on a large scale. The Guidelines also specifically state that the activities of

"a biotechnology company offering genetic tests directly to consumers in order to assess and predict the disease/health risks"

fall under the criteria of "evaluation or scoring, including profiling and predicting" [mentioned in Article 35 (3) of the GDPR] and, therefore, require an impact assessment. ${ }^{38}$ Taking all this into account, it can be concluded that virtually all of the genetic data processing operations posing significant risks to society should be covered by the data protection impact assessment.

However, the feasibility and effectiveness of this assessment, as well as the objectivity of its results are quite another matter. In this regard, Quinn and Quinn point out that, in the case of the processing of a large

${ }^{35}$ See Recital 89 of the GDPR.

36 See Article 35 (3) (b) of the GDPR.

37 Article 29 Data Protection Working Party. (2017) Guidelines on Data Protection Impact Assessment (DPIA) and determining whether processing is "likely to result in a high risk" for the purposes of Regulation 2016/679, 17/EN WP 248, 4 April. Available from: http://ec.europa. eu/newsroom/document.cfm?doc_id=47711 [Accessed 9 March 2020].

38 Op. cit., p. 9. 
amount of genetic information, even a superficial assessment deals with a significant number of aspects. The consideration of all risks to the rights and freedoms of natural persons and the measures envisaged to address the risks, as provided for in Article 35 of the GDPR,

"would be a potentially enormous exercise demanding a truly multi-disciplinary perspective from disciplines such as ethics, law, genetics and sociology". ${ }^{39}$

All of this raises doubts as to whether each data controller would be able to carry out such a procedure, whether the conclusions drawn up as a result of it would be objective and impartial, and as to whether, in general, such a mechanism is an effective way to safeguard the rights of natural persons with regard to the processing of their genetic data.

\subsection{ANONYMISATION AND PSEUDONYMISATION}

The third element of the protection of data subjects' rights according to the GDPR is the anonymisation and pseudonymisation of such data. Pursuant to Recital 26 information related to natural persons is classified into two groups: anonymous information and information concerning an identified or identifiable natural person (i.e. personal data). Furthermore, personal data which have undergone pseudonymisation should be considered as information on an identifiable natural person. This provision has been critically assessed by researchers who used pseudonymised genetic data in their studies and did not protect such data on an equal footing with personal data, as they believe it could have very negative consequences for genetic research. ${ }^{40}$

Article 4 of the GDPR defines pseudonymisation as

"the processing of personal data in such a manner that the personal data can no longer be attributed to a specific data subject without the use of additional information, provided that such additional information is kept separately and is subject to technical and organisational measures".

39 Quinn, P. and Quinn, L. (2018) Big genetic data and its big data protection challenges. Computer Law \& Security Review, 34 (5), p. 1008.

40 Shabani, M. and Borry, P. (2018) Rules for processing genetic data for research purposes in view of the new EU General Data Protection Regulation. European Journal of Human Genetics, 26 (2), p. 151. See also: Mourby, M. et al. (2018) Are 'pseudonymised' data always personal data? Implications of the GDPR for administrative data research in the UK. Computer Law \& Security Review, 34 (2), pp. 222-233. 
It places special emphasis on whether or not third parties are able to identify a person on the basis of such data. In this context, Recital 26 states that

"to determine whether the person is identifiable, account should be taken of all the means and factors reasonably likely to be used [...] to identify the natural person directly or indirectly",

inter alia, such factors as

"the costs of and the amount of time required for identification, taking into consideration the available technology at the time of the processing and technological developments". ${ }^{41}$

Although similar formulations are typical of international documents related to the processing of genetic data, ${ }^{42}$ according to Shabani and Borry

"the existing heterogeneity in pseudonymisation methods [...] could be seen as a potential challenge in implementing the pertinent provisions". ${ }^{43}$

Regarding this issue it is doubtful whether one can correctly anticipate and take into account further technological advances in genetics and bioinformatics in order to draw the objective conclusion as to how much effort and resources would be necessary to identify the person by his or her pseudonymised data even in the near future. That is why the aforementioned provision can be treated as giving the data controller the possibility to rely on pseudonymisation as a guarantee for the protection of data subject rights, even when this procedure is not justified. Moreover, it is not clear what actions should be taken in ahypothetical future situation in which technological advances will make it possible to sharply reduce the time and effort required for identification of a person by his or her pseudonymised data, given the fact that such data will already be accessible to a wider range of persons.

41 See Recital 26 of the GDPR.

42 For example, the Recommendation of the Council of Europe, which contains a number of special provisions on genetic data, states the following: "An individual shall not be regarded as 'identifiable' if identification requires an unreasonable amount of time and manpower". Council of Europe. Committee of Ministers. (1997) Recommendation No. R (97) 5 on the Protection of Medical Data, 30 October, paragraph 1. [online] Available from: https://rm.coe.int/1680505 d5b [Accessed 7 March 2020].

43 Shabani, M. and Borry, P. (2018) Rules for processing genetic data for research purposes in view of the new EU General Data Protection Regulation. European Journal of Human Genetics, 26 (2), p. 151. 
Most of these points relate equally to another kind of depersonalisation of data, namely, anonymisation. Recital 156 and Article 89 of the GDPR relating to the processing of personal data for archiving purposes in the public interest, scientific or historical research purposes or statistical purposes emphasize the need to ensure the principle of data minimisation. In other words, personal data that are used for research purposes should be limited to what is necessary in relation to the purposes for which they are processed, given the obligation to respect the principle of proportionality and taking into consideration the need to use anonymous information wherever possible. The process of anonymising data that is conducted by the controller allows to exclude such data processing operations from the scope of the GDPR and removes the respective obligations of the controller to the data subject. It should be noted that Article 83 of the draft Regulation of 2012, which corresponds to Article 89 of the GDPR, in fact, provided for the explicit obligation to use anonymous information or pseudonyms for historical, statistical and scientific research purposes whenever possible. ${ }^{44}$

The main problem is that data anonymisation and pseudonymisation cannot be considered effective when it comes to the processing of genetic data. In particular, the Opinion 05/2014 on anonymisation techniques adopted by the Article 29 Working Party draws the attention of controllers to the fact that

"an anonymised dataset can still present residual risks to data subjects"

and emphasizes that

"anonymisation should not be regarded as a one-off exercise and the attending risks should be reassessed regularly". ${ }^{4}$

Moreover, the Opinion refers to an example of genetic data, which, even without identifiers directly related to the data subject, can be further linked

44 European Commission. (2012) Proposal for a Regulation of the European Parliament and of the Council on the protection of individuals with regard to the processing of personal data and on the free movement of such data (General Data Protection Regulation), COM/2012/011 final 2012/0011 (COD), 25 January, Article 83. Available from: https://eur-lex.europa.eu/legalcontent/EN/TXT/PDF/?uri=CELEX:52012PC0011\&from=EN [Accessed 9 March 2020].

45 Article 29 Data Protection Working Party. (2014) Opinion 05/2014 on Anonymisation Techniques, 0829/14/EN WP216, 10 April, p. 4. Available from: https:/ec.europa.eu/justice/ article-29/documentation/opinion-recommendation/files/2014/wp216_en.pdf [Accessed 9 March 2020]. 
to him or her, especially in the light of current scientific advances. ${ }^{46}$ In this regard, it is worth mentioning the study conducted by a team of scientists, led by Erlich, a computational geneticist at MIT's Whitehead Institute for Biomedical Research, in which they prove the ability to identify a person by his or her anonymised genetic data, as well as other data from publicly available sources. ${ }^{47}$ Given current technological advances, Quinn and Quinn argue that

"anonymisation of big genetic research data may no longer be considered realistic".

They highlight three main factors making proper anonymisation elusive:

(1) the availability of big genetic data;

(2) the ability of researchers to access and share data around the world;

(3) the growth of computational power, as well as the development of ever more sophisticated identification algorithms.

In other words, the statement "big human genetic data is always personal data" is not far from the truth. ${ }^{48}$

The existing EU data protection legislation does not give sufficient attention to these facts and factors. This affects the corresponding privacy policy of global companies handling large amounts of genetic data, including those of EU citizens. For instance, 23andMe, one of the world's largest genealogy research services companies, relies heavily on data anonymisation and pseudonymisation as safeguards for the protection of the rights and interests of data subjects when using genetic information for scientific research. But in doing so the company also recognizes that though it is difficult to identify the person by his or her de-identified genetic information, but not impossible, and warns about the likelihood of "additional risks that are currently unforeseeable". ${ }^{49}$ Thus, given the current

${ }_{46}$ Op. cit., p. 10.

47 Gymrek, M. et al. (2013) Identifying personal genomes by surname inference. Science, 339, pp. 321-324. See also: Shabani, M. and Marelli, L. (2019) Re-identifiability of genomic data and the GDPR: Assessing the re-identifiability of genomic data in light of the EU General Data Protection Regulation. EMBO Rep, 20: e48316, 5 p. Available from: https://www.embo press.org/doi/10.15252/embr.201948316 [Accessed 7 March 2020].

48 Quinn, P. and Quinn, L. (2018) Big genetic data and its big data protection challenges. Computer Law \& Security Review, 34 (5), p. 1002.

49 23andMe. (2020) Research Consent Document, paragraph 5. [online] Available from: https://www.23andme.com/about/consent [Accessed 9 March 2020]. 
trends in genetic technology, it cannot be argued that the GDPR establishes the rules for the processing of genetic data which are advanced enough to provide an adequate response to the challenges ahead.

\section{RESEARCH EXEMPTION}

One of the most significant and controversial innovations of the GDPR is the introduction of the research exemption. This is about the relaxation of the rules on the handling of personal data, including derogations from the rights of the data subject when the processing of data is carried out

"for archiving purposes in the public interest, scientific or historical research purposes or statistical purposes".

For comparison, Directive 95/46/EC did not provide for the general research exemption with respect to sensitive data, but member states had the right to lay down such exemptions for reasons of substantial public interest. ${ }^{50}$

Exemptions to the principles of the protection of personal data and restrictions of the rights of the data subject in the interest of science are found in several articles of the GDPR. In particular, Article 5 stipulates that the further data processing is allowed for scientific research purposes and shall not be considered as incompatible with the initial purposes (i.e. it allows exception to the purpose limitation principle) ${ }^{51}$ and states that personal data may be stored for longer periods for such purposes (exception to the principle of storage limitation). ${ }^{52}$ Article $9(2)(\mathrm{j})$ establishes the research exemption to the general prohibition on the processing of special categories of personal data. Moreover, Article 14 (5) sets out an exception to the obligation of the data controller to provide the data subject with relevant information, where personal data have not been obtained from him or her, in cases where the provision of such information would involve a disproportionate effort for processing for archiving, scientific or historical research purposes. The same applies to the right of the data subject to have his or her personal data erased ("right to be forgotten") specified in Article 17. Article 21 (6) allows for the derogation from the right to object in cases where data processing for scientific research

50 See Article 8 (4) of the Directive 95/46/EC.

51 For more on this issue, see Mészáros, J. and Ho, C. (2018) Big Data and Scientific Research: The Secondary Use of Personal Data under the Research Exemption in the GDPR. Hungarian Journal of Legal Studies, 59 (4), pp. 403-419.

52 See Article 5 (1) (b) and (e) of the GDPR. 
purposes is necessary for the performance of a task carried out for reasons of public interest. Finally, under Article 89 (2), Union or member state law may provide for derogations from a number of basic rights of the data subject (namely, the right of access, the right to rectification, the right to restriction of processing, and the right to object)

"in so far as such rights are likely to render impossible or seriously impair the achievement of the specific purposes, and such derogations are necessary for the fulfilment of those purposes".

In addition, the research exemption is mentioned in several Recitals (50, 52, $53,62,65$, and 113). ${ }^{53}$

As provided for in Article 89 and Recital 156, the legal safeguards protecting personal data from misuse for scientific research purposes amount to data minimisation, anonymisation, and pseudonymisation. Based on the above-mentioned considerations on the effectiveness of these tools when it comes to the processing of genetic data, it can be concluded that the GDPR provides favourable conditions for genetic research, while the rights of the data subjects with regard to the processing of their genetic data for scientific research purposes are threatened and are not clearly defined. In this respect, Pormeister asserts that even the title of Article 89 is somewhat misleading, because it refers to both safeguards and derogations relating to the processing of personal data under the research exemption, but

"a closer look will reveal that the referred article is more about derogations, and less about safeguards". ${ }^{4}$

It is worth noting that corresponding article of the draft Regulation of 2012 provided for more stringent conditions for research and relied on a rigorous rule - "data subject's consent or anonymisation"..$^{5}$

Another important aspect refers to the definition of "scientific research" under the GDPR. In this respect, Recital 159 stipulates that

\footnotetext{
53 In this regard, Pormeister claims that wide discretionary powers of member states to provide derogations from a number of data protection rights lead to significant differences between national laws concerning genetic research and, thus, threaten the interests of both data subjects and researchers. Pormeister, K. (2018) Genetic research and applicable law: the intra-EU conflict of laws as a regulatory challenge to cross-border genetic research. Journal of Law and the Biosciences, 5 (3), pp. 706-723.

54 Pormeister, K. (2017) Genetic data and the research exemption: is the GDPR going too far? International Data Privacy Law, 7 (2), p. 140.
} 


\begin{abstract}
"the processing of personal data for scientific research purposes should be interpreted in abroad manner including for example technological development and demonstration, fundamental research, applied research and privately funded research".
\end{abstract}

The references to the public interest are omitted in a number of provisions providing the research exemption. This makes it possible to apply it to nearly all research, including the one conducted solely for commercial purposes.

It should be noted that when drafting the GDPR, various stakeholders drew attention to this issue. In particular, Recital 126 of the Position of the European Parliament of 2014 with a view to the adoption of the GDPR (that corresponds to Recital 159 of the GDPR) contained the following wording:

"The processing of personal data for historical, statistical and scientific research purposes should not result in personal data being processed for other purposes, unless with the consent of the data subject or on the basis of Union or Member State law". 56

The Position paper on the GDPR of the Biobanking and BioMolecular resources Research Infrastructure - European Research Infrastructure Consortium stresses the need for a clear distinction between research in the public interest and commercially oriented research and applying the exemption only to the first one. ${ }^{57}$ With respect to this matter, Pormeister refers to the Estonian legislation on personal data protection, under which scientific research

55 European Commission. (2012) Proposal for a Regulation of the European Parliament and of the Council on the protection of individuals with regard to the processing of personal data and on the free movement of such data (General Data Protection Regulation), COM/2012/011 final 2012/0011 (COD), 25 January, Article 83. Available from: https://eur-lex.europa.eu/legalcontent/EN/TXT/PDF/?uri=CELEX:52012PC0011\&from=EN [Accessed 9 March 2020].

56 European Parliament legislative resolution of 12 March 2014 on the proposal for a regulation of the European Parliament and of the Council on the protection of individuals with regard to the processing of personal data and on the free movement of such data (General Data Protection Regulation). Official Journal of the European Union (2017/C-378/399) 9 November. Available from: https://eur-lex.europa.eu/legal-content/EN/TXT/PDF/?uri= CELEX:52014AP0212\&from=EN [Accessed 7 March 2020].

57 BBMRI-ERIC (Biobanking and BioMolecular resources Research Infrastructure - European Research Infrastructure Consortium). (2015) Position Paper on the General Data Protection Regulation, p. 8. [online] Available from: https://www.bbmri-eric.eu/wp-content/uploads/ BBMRI-ERIC-Position-Paper-General-Data-Protection-Regulation-October-2015_rev1_title. pdf [Accessed 9 March 2020]. See also: Shabani, M. and Borry, P. (2018) Rules for processing genetic data for research purposes in view of the new EU General Data Protection Regulation. European Journal of Human Genetics, 26 (2), p. 153. 
means only the one carried out by research and development institutions excluding privately founded companies. ${ }^{58}$

On the other hand, it cannot be argued that the research exemption established by the GDPR is completely unfounded. It is usually justified by the arguments arising from the peculiarities of scientific inquiry in the fields of genetics and bioinformatics. This refers, for example, to the requirement for the publication of genetic data together with genetic research findings in order to allow other scientists to verify the results and to download the data for their own further research, as well as to the impossibility of determining ahead of time the exact purpose of genetic data processing or the duration of the research. At the same time, the data minimisation principle is considered to be scarcely compatible with genetic studies, because, as pointed out by Quinn and Quinn, in order to achieve the required result scientists often need "the entire haystack to find the needle". ${ }^{59}$ In most cases, it is difficult to obtain the informed consent of all data subjects whose genetic data are used by research institutions, taking into account, inter alia, the unfeasibility of identifying all those who have undergone genetic testing and the fact that the direct identifiers associated with the persons involved have been removed. ${ }^{60}$ In their privacy policy statements, companies that process large amounts of genetic data express doubts about the practical applicability of many of personal data processing rules. For instance, 23andMe provides restrictions on such rights as the right to erasure and the right to withdraw consent. Namely, genetic data that a customer has previously provided and for which he or she has given consent to use in 23andMe's research project cannot be removed from ongoing or completed studies that use such information. ${ }^{61}$

The GDPR states that the

"processing of personal data should be designed to serve mankind"

58 Pormeister, K. (2017) Genetic data and the research exemption: is the GDPR going too far? International Data Privacy Law, 7 (2), p. 145.

59 Quinn, P. and Quinn, L. (2018) Big genetic data and its big data protection challenges. Computer Law \& Security Review, 34 (5), pp. 1006-1007.

${ }^{60}$ It is worth noting once again that this does not mean that it is impossible to identify each individual person. Thus, the existence of such "anonymised" data creates certain risks for data subjects.

${ }_{61}$ 23andMe. (2020) Research Consent Document. [online] Available from: https://www.23and me.com/about/consent [Accessed 9 March 2020]; 23andMe. (2018) Exercising Rights Under the GDPR. Right to Erasure (Right to Be Forgotten). [online] Available from: https://perma links.23andme.com/pdf/toolkit/erasure.pdf [Accessed 9 March 2020]. 
and that the right to the protection of personal data

"must be considered in relation to its function in society and be balanced against other fundamental rights, in accordance with the principle of proportionality". ${ }^{62}$

Thus, the primary aim of the GDPR is to ensure the necessary and appropriate preconditions for such balancing, taking into account, inter alia,

(1) the abstract weight of each principle,

(2) the intensity of interference with them, and

(3) the reliability of the empirical assumptions. ${ }^{63}$

Regarding the abstract weight, scientific genetic research is, of course, of special importance for society. It serves the substantial public interest and meets the legitimate expectations of society for an increase of knowledge. ${ }^{64}$ However, the right to the protection of personal data and the right to privacy are important not only for a particular individual, but also for a society as a whole, ${ }^{65}$ as the ensuring of these rights is an essential condition for the competitive economy, democratic governance and civic sector development. The extensive research exemption established by the GDPR and the existing safeguards for the right to the protection of personal data, which may prove to be not very strong and reliable, ${ }^{66}$ make it look like the abstract weight of the public interest in scientific research is much greater, but it is not fully justified.

Referring to the intensity of interference, it is important to note that the implementation of an outdated principle "consent or anonymisation" would inevitably lead to a significant interference with genetic research and would greatly impede the fulfilment of the public interest. However, the current provisions of the GDPR also create the preconditions for significant interference with the right to the protection of personal data, and the situation is likely to deteriorate due to the further technological

62 See Recital 4 of the GDPR.

63 Alexy, R. (2003) On Balancing and Subsumption. A Structural Comparison. Ratio Juris, 16 (4), pp. 433-449.

${ }^{64}$ See Recital 113 of the GDPR.

65 Taylor, M. (2012) Genetic Data and the Law: A Critical Perspective on Privacy Protection. Cambridge: Cambridge University Press, p. 13.

66 Staunton, C., Slokenberga, S. and Mascalzoni, D. (2019) The GDPR and the research exemption: considerations on the necessary safeguards for research biobanks. European Journal of Human Genetics, 27, pp. 1159-1167. 
developments ${ }^{67}$ As for the reliability of the empirical assumptions, it is not uncommon, even nowadays, to find evidence of the uncontrolled accumulation of genetic data, including linking them with other categories of personal data. Given the rapid scientific and technological developments in this field ${ }^{68}$ and the aforementioned characteristics of genetic data, the emergence of new evidence of the interference with the rights of the natural person concerning the processing of their genetic data should be expected in the near future.

\section{CONCLUSIONS}

The emergence of legal norms on the protection of genetic data in the EU legislation is both a natural consequence of the progress in biological and information technologies, which have caused a marked increase in the processing of such data by various companies and institutions, and an attempt to respond to human rights-related challenges. Most significant developments of the GDPR on genetic data include the clear and unambiguous assignment of such data to special categories of personal data, the introduction of a compulsory procedure of data protection impact assessment, and the settlement of the issue of pseudonymised data. Besides, it can be argued that current EU data protection legislation creates favourable conditions for genetic research and thus safeguards particular public interests.

However, the insufficient attention to the unique characteristics of genetic data distinguishing them from other categories of personal data, which are already mentioned in several authoritative international documents, can be considered as one of the main weaknesses of the GDPR. The consequence of this is the lack of specific regulation establishing a particular regime for genetic data processing appropriate to potential risks and threats in this field. A number of important aspects regarding the processing of genetic data, that over the last three decades have been repeatedly highlighted by various researchers, experts, and officials, fall outside the scope of the GDPR. This applies primarily to the comprehensive protection of genetic data and biological samples, the ensuring of rights

${ }^{67}$ For more on the far-reaching threats posed by big genetic data, see: Sorgner, S. L. (2017) Genetic Privacy, Big Genetic Data, and the Internet Panopticon. Journal of Posthuman Studies, 1 (1), pp. 87-103.

68 Korf, B. (2013) Genomic privacy in the Information age. Clinical Chemistry, 59 (8), pp. $1148-1150$. 
of the persons related to the data subject ("secondary data subjects"), the lack of efficiency of data anonymisation and pseudonymisation, etc. The extensive research exemption together with the broadest interpretation of scientific research may lead to significant derogations from the rights of the data subject. Under such conditions, much depends on member states which can introduce further limitations regarding the processing of genetic data and on data controllers that are to take into account existing risks to the rights of natural persons and to implement appropriate genetic data protection policies. Still, it cannot substitute for legislative guarantees of the rights of data subject at the EU level.

The root of the problem is that the commonly accepted standards of conducting genetic research are in many respects incompatible with the key principles of legislation ensuring privacy and personal data protection. By adopting the GDPR, the European Union made an attempt to reconcile these contradictory principles by moving beyond the previous approach relying exclusively on the data subject's consent and data anonymisation, that is scarcely compatible with contemporary genetic research. However, this could lead to the major imbalances between various private and public interests. Due to the above, the following trend can be discerned: the control over personal information is gradually slipping away from the data subject while the impact of genetic technology on society is becoming more and more apparent.

\section{LIST OF REFERENCES}

[1] 23andMe. (2018) Exercising Rights Under the GDPR. Right to Erasure (Right to Be Forgotten). [online] Available from: https://permalinks.23andme.com/pdf/toolkit/erasure.pdf [Accessed 9 March 2020].

[2] 23andMe. (2020) Privacy Highlights. [online] Available from: https://www.23andme.com/ about/privacy [Accessed 9 March 2020].

[3] 23andMe. (2020) Research Consent Document. [online] Available from: https://www.23and me.com/about/consent [Accessed 9 March 2020].

[4] Alexy, R. (2003) On Balancing and Subsumption. A Structural Comparison. Ratio Juris, $16(4)$.

[5] Article 29 Data Protection Working Party. (2004) Working Document on Genetic Data, 12178/03/EN WP 91, 17 March. Available from: https://ec.europa.eu/justice/article-29/ 
documentation/opinion-recommendation/files/2004/wp91_en.pdf [Accessed 9 March 2020].

[6] Article 29 Data Protection Working Party. (2014) Opinion 05/2014 on Anonymisation Techniques, 0829/14/EN WP216, 10 April. Available from: https:/ec.europa.eu/justice/ article-29/documentation/opinion-recommendation/files/2014/wp216_en.pdf

[Accessed 9 March 2020].

[7] Article 29 Data Protection Working Party. (2017) Guidelines on Data Protection Impact Assessment (DPIA) and determining whether processing is "likely to result in a high risk" for the purposes of Regulation 2016/679, 17/EN WP 248, 4 April. Available from: http://ec. europa.eu/newsroom/document.cfm?doc_id=47711 [Accessed 9 March 2020].

[8] BBMRI-ERIC (Biobanking and BioMolecular resources Research Infrastructure European Research Infrastructure Consortium). (2015) Position Paper on the General Data Protection Regulation. [online] Available from: https://www.bbmri-eric.eu/wp-content/ uploads/BBMRI-ERIC-Position-Paper-General-Data-Protection-Regulation-October-2015 _rev1_title.pdf [Accessed 9 March 2020].

[9] Borry, P. et al. (2018) The Challenges of the Expanded Availability of Genomic Information: An Agenda-Setting Paper. The Journal of Community Genetics, 9 (2).

[10] Council of Europe. (2018) Convention 108+ (Modernised Convention for the Protection of Individuals with Regard to the Processing of Personal Data), 21 June. Available from: https://www.europarl.europa.eu/meetdocs/2014_2019/plmrep/COMMITTEES/LIBE/DV/ 2018/09-10/Convention_108_EN.pdf [Accessed 7 March 2020].

[11] Council of Europe. Committee of Ministers. (1997) Recommendation No. $R$ (97) 5 on the Protection of Medical Data, 30 October. Available from: https://rm.coe.int/1680505d 5b [Accessed 7 March 2020].

[12] De Paor, A. (2017) The European Union and Protection of Genetic Information. In: De Paor, A. (ed.). Genetics, Disability and the Law: Towards an EU Legal Framework. Cambridge: Cambridge University Press (Cambridge Disability Law and Policy Series).

[13] Directive 95/46/EC of the European Parliament and of the Council of 24 October 1995 on the protection of individuals with regard to the processing of personal data and on the free movement of such data. Official Journal of the European Communities (1995/L-281/31) 23 November. Available from: https://eur-lex.europa.eu/legal-content/EN/TXT/ PDF/?uri=CELEX:31995L0046\&from=en [Accessed 7 March 2020].

[14] European Commission. (2012) Proposal for a Regulation of the European Parliament and of the Council on the protection of individuals with regard to the processing of personal data and 
on the free movement of such data (General Data Protection Regulation), COM/2012/011 final2012/0011 (COD), 25 January. Available from: https://eur-lex.europa.eu/legal-content/EN/ TXT/PDF/?uri=CELEX:52012PC0011\&from=EN [Accessed 9 March 2020].

[15] European Parliament legislative resolution of 12 March 2014 on the proposal for a regulation of the European Parliament and of the Council on the protection of individuals with regard to the processing of personal data and on the free movement of such data (General Data Protection Regulation). Official Journal of the European Union (2017/C-378/399) 9 November. Available from: https://eur-lex.europa.eu/legal-content/EN /TXT/PDF/?uri=CELEX:52014AP0212\&from=EN [Accessed 7 March 2020].

[16] European Parliament. Committee on Petitions. (2019) Petition No 0733/2018 by J.B. (Portuguese) on improving the protection of genetic data related to European Union citizens, 15 March. Available from: https://www.europarl.europa.eu/doceo/document/PETI-CM637225_EN.pdf [Accessed 7 March 2020].

[17] Gymrek, M. et al. (2013) Identifying personal genomes by surname inference. Science, 339.

[18] Korf, B. (2013) Genomic privacy in the Information age. Clinical Chemistry, 59 (8).

[19] Mészáros, J. and Ho, C. (2018) Big Data and Scientific Research: The Secondary Use of Personal Data under the Research Exemption in the GDPR. Hungarian Journal of Legal Studies, 59 (4).

[20] Mourby, M. et al. (2018) Are 'pseudonymised' data always personal data? Implications of the GDPR for administrative data research in the UK. Computer Law E Security Review, $34(2)$.

[21] MyHeritage. (2019) MyHeritage Privacy Policy. [online] Available from: https://www.my heritage.com/privacy-policy [Accessed 9 March 2020].

[22] Pormeister, K. (2017) Genetic data and the research exemption: is the GDPR going too far? International Data Privacy Law, 7 (2).

[23] Pormeister, K. (2018) Genetic research and applicable law: the intra-EU conflict of laws as a regulatory challenge to cross-border genetic research. Journal of Law and the Biosciences, 5 (3).

[24] Quinn, P. and Quinn, L. (2018) Big genetic data and its big data protection challenges. Computer Law \& Security Review, 34 (5).

[25] Regalado, A. (2019) More than 26 million people have taken an at-home ancestry test. MIT Technology Review. [online] Available from: https://www.technologyreview.com/s/ 
612880/more-than-26-million-people-have-taken-an-at-home-ancestry-test/

[Accessed 7 March 2020].

[26] Regulation (EU) 2016/679 of the European Parliament and of the Council of 27 April 2016 on the protection of natural persons with regard to the processing of personal data and on the free movement of such data, and repealing Directive 95/46/EC (General Data Protection Regulation). Official Journal of the European Union (2016/L-119/1) 4 May. Available from: https:/eur-lex.europa.eu/legal-content/EN/TXT/PDF/?uri=CELEX:32016 R0679\&from=EN [Accessed 7 March 2020].

[27] Shabani, M. and Borry, P. (2018) Rules for processing genetic data for research purposes in view of the new EU General Data Protection Regulation. European Journal of Human Genetics, 26 (2).

[28] Shabani, M. and Marelli, L. (2019) Re-identifiability of genomic data and the GDPR: Assessing the re-identifiability of genomic data in light of the EU General Data Protection Regulation. EMBO Rep, 20: e48316, 5 p. [online] Available from: https://www.embopress.org/doi/ 10.15252/embr.201948316 [Accessed 7 March 2020].

[29] Sorgner, S. L. (2017) Genetic Privacy, Big Genetic Data, and the Internet Panopticon. Journal of Posthuman Studies, 1 (1).

[30] Staunton, C., Slokenberga, S. and Mascalzoni, D. (2019) The GDPR and the research exemption: considerations on the necessary safeguards for research biobanks. European Journal of Human Genetics, 27.

[31] Taylor, M. (2012) Genetic Data and the Law: A Critical Perspective on Privacy Protection. Cambridge: Cambridge University Press.

[32] United Nations Educational, Scientific and Cultural Organization. (2003) International Declaration on Human Genetic Data, SHS/BIO/04/1, 16 October. Available from: http://portal.unesco.org/en/ev.php-URL_ID=17720\&URL_DO=DO_TOPIC\&URL_ SECTION=201.html [Accessed 9 March 2020]. 